\title{
Methods for Analysis of
}

Selected Metals in

Water by Atomic Absorption

GEOLOGICAL SURVEY WATER-SUPPLY PAPER 1540-C

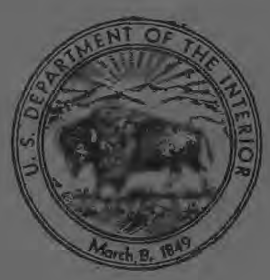




\section{Methods for Analysis of}

Telected Metals in

Vater by Atomic Absorption

E. MARVIN J. FISHMAN and SANFORD C. DOWNS

SPECTROGRAPHIC ANALYSIS OF NATURAL WATER

GEOLOGICAL SURVEY WATER-SUPPLY PAPER 1540-C

A manual of procedures for determining calcium, copper, lithium, magnesium, manganese, potassium, sodium, strontiim, and zinc in atmospheric precipitaiion, fresh waters, and brines by atomic absorption spectroscopy

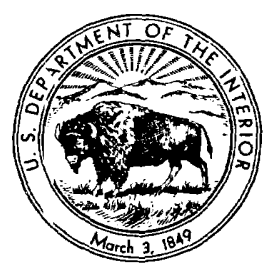




\section{UNITED STATES DEPARTMENT OF THE II TERIOR}

STEWART L. UDALL, Secretary

\section{GEOLOGICAL SURVEY}

William T. Pecora, Director 


\section{CONTENTS}

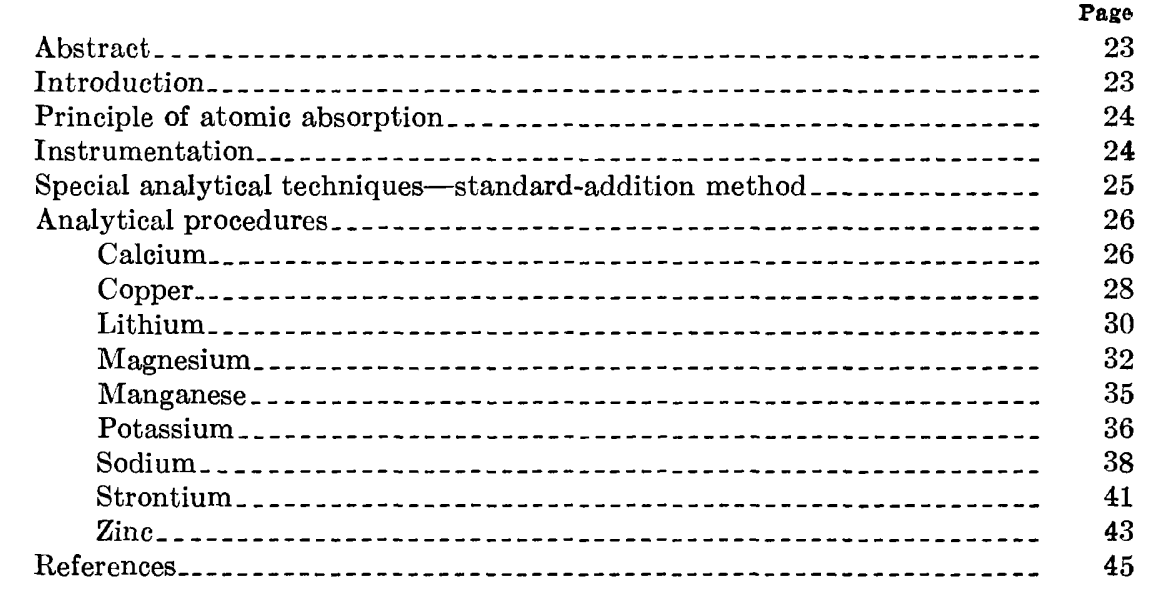

\section{ILLUSTRATIONS}

Figure 3. Schematic diagram of Perkin-Elmer Model 303 atomic alsorpspectrophotometer optical system _...

4. Diagram showing example of standard-addition method _..... 



\title{
SPECTROGRAPHIC ANALYSIS OF NATURAL WATER
}

\section{METHODS FOR ANALYSIS OF SELEGTED METALS IN WATER BY ATOMIC ABSORPTION}

\author{
By Marvin J. Fishman and Sanford C. Downs
}

\section{ABSTRACT}

This manual describes atomic-absorption-spectroscopy methods for dotermining alcium, copper, lithium, magnesium, manganese, postassium, sodium. strontium. and zinc in atmospheric precipitation, fresh waters, and brines. The procedures are intended to be used by water quality laboratories of the Water Resources Jirision of the U.S. Geological Survey. Detailed procedures, calculstions, and methods for the preparation of reagents are given for each element along with data on accuracy, precision, and sensitivity. Other topies discussed briefly are the principle of atomic absorption, instrumentation used, and special analytical rechniques.

\section{INTRODUCTION}

The purpose of this manual is to describe atomic-absorptior methods of water analysis to be used by water quality laboratories of the Water ?esources Division of the U.S. Geological Survey and to stendardize procedures by serving as a guide for laboratory personnel. The procedures in this manual are applicable to the analysis of most natural raters, and some of them are applicable to the analysis of brines. If a zarticular element can be determined in a brine and if sufficient data 'o support this determination are available, the individual procedure is discussed. Determinations of other elements that cannot be supported by current data are not discussed. Because atomic absorption permits -ery low detection limits, precipitation waters can be analyzed readily by the procedures presented. Most of the procedures in this manual "ere adapted from the Perkin-Elmer instruction manual. (1964). Todifications have been made where necessary to adapt the procedures o water analysis. Additional information may be obtained from the manufacturer's manual.

The use of trade names of equipment, supplies, and reagents in this manual does not constitute endorsement. It is done only in tha interest of standardization. 


\section{PRINCIPLE OF ATOMIC ABSORPTION}

It has been known for more than a hundred years that atoms of some elements are excited when vaporized and fed into a flame. As these atoms return to their ground state, they emit radiation of characteristic measurable wavelengths. This principle is the basis for flameemission photometry.

Most elements are not easily excited in a flame, and most of the atoms remain in the ground state. These unexcited atoms can absorb energy from a beam of light of the same characteristic warelength. The beam of light from a hollow-cathode lamp made of the metal being determined was used by Walsh (1955) to develop atomic-absorption instrumentation. He found that a source of radiation of the same wavelength as that of the absorption line puts less demand upon the resolution of the monochromator than a source of broadband radiation. Since the wavelength of the light beam is characteristic of only the metal being determined, the light energy absorbed by the flame is a measure of the concentration of that metal in the sample. This principle is the basis of atomic absorption spectroscopy.

\section{INSTRUMENTATION}

Several manufacturers currently supply atomic-sbsorption equipment. Among them are Jarrell-Ash, Beckman, Aztec, Hilger and Watts, Unicam, and Perkin-Elmer. Instruments offered by these manufacturers differ in design.

The selection of a given commercial product is base 1 largely upon its design, durability, cost, and maintenance requiremants, but also on standardization of equipment in all water quality laboratories of the TVater Resources Division of the U.S. Geological Survey. Experience gained in individual laboratories, is evaluated, and the results are used by other laboratories.

A schematic diagram of the Perkin-Elmer optical system is shown in figure 3. The energy or light beam from the source, either a hollowcathode or vapor-discharge lamp, is divided by a rotating chopper into a reference beam and a sample beam. The water sample is aspirated into an atomizer-burner, and part of the sample beam passing through the flame is absorbed, the amount depending upon the concentration of the metal being determined. The remainder of tlo sample beam is recombined with the reference beam by a semitransparent mirror. The analytical wavelength of the metal being analyze $\mathrm{f}$ is isolated from all other energy in the light beam by a grating monochromator. Two gratings are mounted back to back-one for the ultraviolent region and the other for the visible region. The extent to which the energy of the characteristic emission wavelength of the source lamp is 


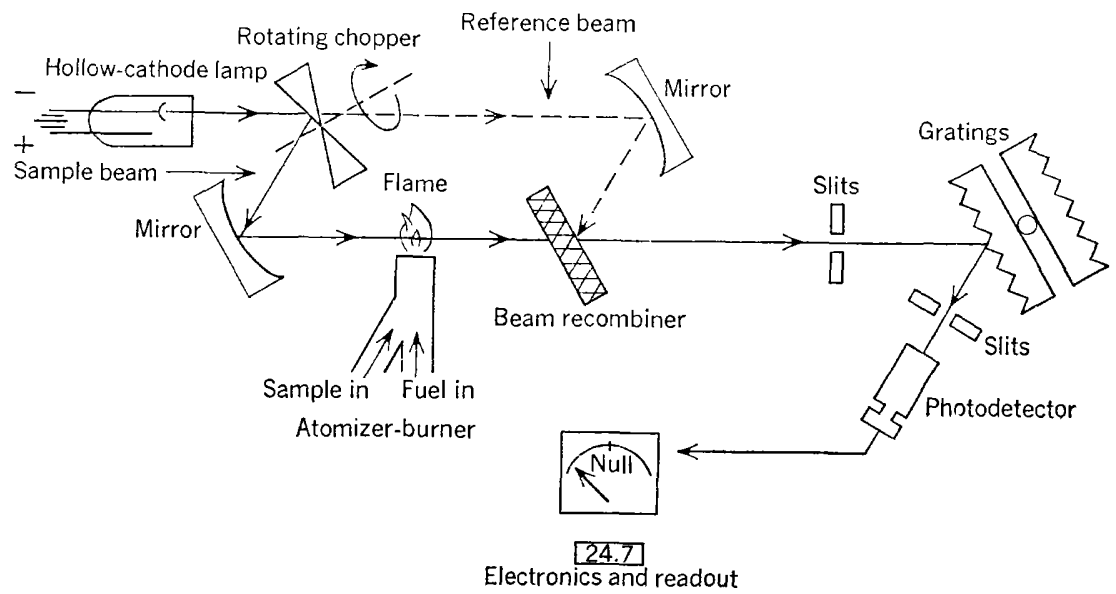

FigdRE 3.-Perkin-Elmer Model 303 atomic absorption spectrophotometer optical system. Reprinted by permission of Perkin-Elmer Corp.

absorbed in the flame is measured by a photodetector. The signal from the photodetector is amplified and fed into circuitry that produces a manual electronic null in combination with a digital readout which corresponds to the concentration of the metal being determined.

By varying the relative proportions of fuel and air in the atomizerburner, an oxidizing (air-rich) or a reducing (fuel-rich) flame is produced. The type of flame to be used depends upon the motal being analyzed. An oxidizing flame is preferable because of its greater stability. However, some metals tend to form refractory oxides in an oxidizing flame, and a reducing flame is necessary to increase the number of atoms available for absorption. The type of flame to be used is stated in each procedure under the operating conditions.

\section{SPECIAL ANALYTICAL TECHNIQUES- STANDARD-ADDITION METHOD}

The standard-addition technique is used when the solids content of the sample is so high that its affect on absorption is difficult to duplicate with the aqueous standards or when an interference is present which cannot be corrected.

Equal volumes of the sample are added to a blank (distilled water) and to three standards containing different known quantities of the test element. The blank and standards must first be diluted tc the same volume. The percentage of absorption of each solution is determined and converted to the corresponding absorbance unit. Absorbance is then plotted against concentration on a graph, and the resulting line is extended back through zero absorbance. The intercept on the concentration axis is the concentration of the metal in the original sample. 
The line should preferably be straight to insure accurate analyses. An example of the standard-addition technique is shown in figure 4.

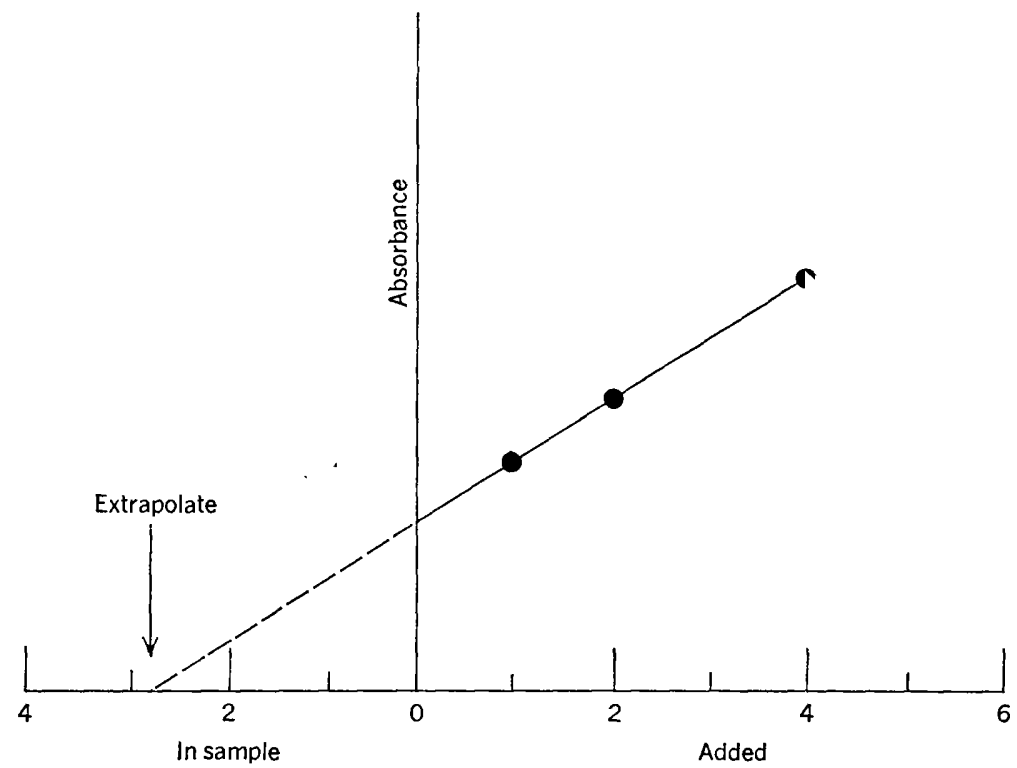

Concentration, in milligrams per liter

Figure 4.-Example of standard-addition method.

\section{ANALYTICAL PROCEDURES}

A Perkin-Elmer Model 303 atomic absorption srectrophotometer was used to determine each metal.

\section{CALCIUM}

\section{DISCUSSION OF METHOD}

A hollow-cathode lamp and a reducing flame are used to determine calcium. Phosphate, sulfate, and aluminum interfer 3 but are masked by the addition of a 1-percent lanthanum solution to the sample. Low calcium values result if the $\mathrm{pH}$ of the sample is above 7 ; therefore, both standards and samples are prepared in 5-percent hydrochloric acid solution. Magnesium in concentrations higher than $1,000 \mathrm{ppm}$ (parts per million) also causes low calcium values. Concentrations of up to $500 \mathrm{ppm}$ each of sodium, potassium, and nitrate show no interference.

The 4227 A (angstrom) line is used to determine concentrations of calcium less than $20 \mathrm{mg}$ per 1 (milligrams per liter). For concentrations of calcium greater than $20 \mathrm{mg}$ per l, dilution is required. The calcium lamp is extremely quiet, and the results of the method are 
accurate and reproducible to $\pm 0.1 \mathrm{mg}$ per $\mathrm{l}$ for concentrations of calcium less than $20 \mathrm{mg}$ per $\mathrm{l}$ and to $\pm 0.2- \pm 1.0 \mathrm{mg}$ per $\mathrm{l}$ for concentrations of calcium from 20 to $200 \mathrm{mg}$ per 1 . When excessive dilution is required, the accuracy and reproducibility are decreased. There is excellent agreement between results obtained by atomic absorption and by EDTA ${ }^{1}$ titration.

The sensitivity for calcium concentrations of less than $20 \mathrm{mg}$ per 1 ranges from 0.15 to $0.30 \mathrm{mg}$ per 1 per 1 percent absorption. With scale expansion concentrations of calcium less than $1 \mathrm{mg}$ per 1 can be determined with an accuracy of $\pm 0.01 \mathrm{mg}$ per 1 .

Grating: Visible

\section{APPARATUS}

Wavelength counter: 211.4 (4227 A)

Scale: $1 \times$

Slit: $5(3 \mathrm{~mm}, 40 \mathrm{~A})$

Source: Calcium hollow-cathode lamp

Lamp current: $10 \mathrm{ma}$ (milliampere)

Air pressure: 28 psi (pounds per square inch); 8.0 on flowmeter

Fuel: Acetylene. Pressure : 8 psi; 9.0 on flowmeter initially (use a $10 \mathrm{mg}$ calcium per liter standard solution and adjuct acetylene flow rate to obtain maximum absorption)

Flame: Reducing

Sample uptake: About $4 \mathrm{ml}$ per min (milliliters per minute) The following absorption readings have been observed:

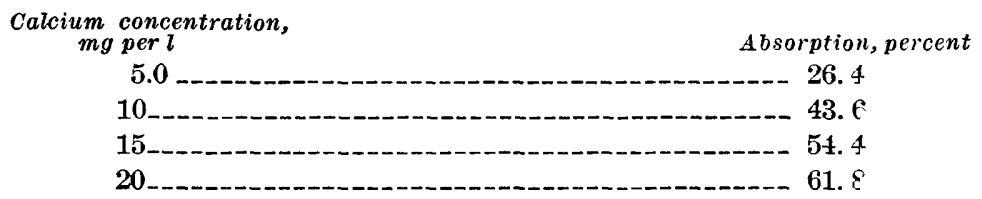

\section{REAGENTS}

Calcium chloride standard stock solution, $1.00 \mathrm{ml}=0.50 \mathrm{mg}$ calcium : Suspend $1.250 \mathrm{~g} \mathrm{CaCO}_{3}$, dried at $180^{\circ} \mathrm{C}$ for 1.0 hour before weighing, in distilled water and dissolve cautiously with a minimum of dilute $\mathrm{HCl}$. Dilute to $1,000 \mathrm{ml}$ with distilled water.

Calcium chloride standard working solutions: Prepare a series of standard solutions containing from 0 to $20 \mathrm{mg}$ calcium per liter by diluting the $\mathrm{CaCl}_{2}$ standard stock solution. Add $1.0 \mathrm{ml}$ of $\mathrm{LaCl}_{3}$ $\mathrm{HCl}$ solution to each $10.0 \mathrm{ml}$ working standards prepared. For example, to $500 \mathrm{ml}$ of a working standard, add $50 \mathrm{ml} \mathrm{LaCl}{ }_{3}-\mathrm{HCl}$ solution.

${ }^{2}$ Ethylenediaminetetraacetic acid.

$223-850-66-2$ 
Lanthanum chloride-hydrochloric acid solution: Dissolve $58.65 \mathrm{~g}$ of $\mathrm{La}_{2} \mathrm{O}_{3}$, slowly and in small portions, in $250 \mathrm{ml}$ concentrated $\mathrm{HCl}$ (CAUTION! Reaction is violent) and dilute to $500 \mathrm{ml}$ with distilled water.

\section{PROCEDURE}

1. Filter the sample $(0.45 \mu$ (micron) micropore membrane filter) when necessary to a void clogging the atomizer-burner.

2. Add $1.0 \mathrm{ml}$ of $\mathrm{LaCl}_{3}-\mathrm{HCl}$ solution to $10.0 \mathrm{ml}$ of sample.

3. Atomize each sample and standard, and record the percent absorption observed. Repeat, and average the two values. If the calcium concentration is greater than $20 \mathrm{mg}$ per l, the sample must be diluted. Be sure that the diluted sample contains the proper amount of $\mathrm{LaCl}_{3}-\mathrm{HCl}$ solution.

\section{CaLCULATIONS}

1. Convert percent absorption to absorbance and determine the calcium concentration in the sample from a plot of absorbances of standards. For samples containing more than $20 \mathrm{mg}$ calcium per liter, multiply by the proper dilution factor. Exact reproducibility is not obtained, and a working curve must be prepared with each set of samples.

2. $\mathrm{ppm}$ calcium $=\frac{1}{\text { density }} \times \mathrm{mg}$ calcium per liter.

Report calcium concentrations less than $10 \mathrm{ppm}$ to the nearest $0.1 \mathrm{ppm}$, those between 10 and $200 \mathrm{ppm}$ to the nearest whole number, and those greater than $200 \mathrm{ppm}$ to two significant figures.

\section{COPPER}

\section{DISCUSSION OF METHOD}

A hollow-cathode lamp operating at $3247 \mathrm{~A}$ is used to determine copper. Allow the lamp to warm up for about 30 minutes at a current of 15 ma before use.

Cations and anions normally found in water do not interfere. To determine copper concentrations less than $1.0 \mathrm{mg}$ per $1,10 \times$ scale expansion is used, and the results are accurate and reproducible to approximately $\pm 0.02 \mathrm{mg}$ of copper per liter. Concentrations of copper greater than $1.0 \mathrm{mg}$ per $\mathrm{l}$ can be determined by using less scale expansion. The maximum copper concentration that, can be determined at the 3247 A line without dilution is approximately $20 \mathrm{mg}$ per 1 .

The sensitivity for copper concentrations of less then $1.0 \mathrm{mg}$ per 1 is approximately $0.02 \mathrm{mg}$ per 1 for each scale division. 


\section{APPARATUS}

Grating: Ultraviolet

Wavelength counter : 324.7 ( $3247 \mathrm{~A})$

Scale : $10 \times$

Slit : 4 (1 mm, $6.5 \mathrm{~A})$

Source: Copper hollow-cathode lamp

Lamp current : 15 ma, or optimum operating current

Air pressure: $28-30 \mathrm{psi} ; 9.0$ on flowmeter (varies with different flowmeters and burners)

Fuel : Acetylene. Pressure : 8 psi ; 9.0 on flowmeter

Flame: Oxidizing

Sample uptake : $2-5 \mathrm{ml}$ per $\mathrm{min}$

Response-time control: 1

The following readings have been observed:

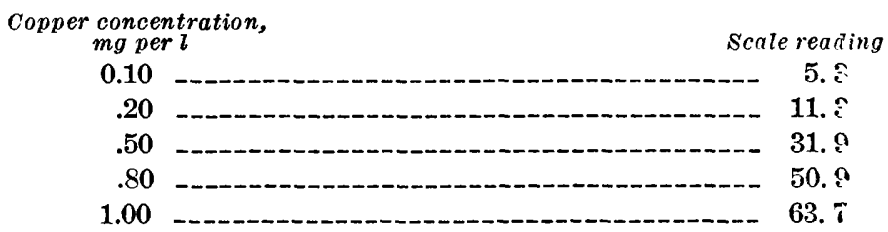

REA GENTS

Copper nitrate standard solution $\mathrm{I}, 1.00 \mathrm{ml}=1.00 \mathrm{mg}$ copper : Dissolve $1.00 \mathrm{~g}$ metallic copper in a slight excess of dilute $\mathrm{HNO}_{3}$, and dilute to $1,000 \mathrm{ml}$ with metal-free water.

Copper nitrate standard solution II, $1.00 \mathrm{ml}=0.005 \mathrm{mg}$ copper : Dilute $5.00 \mathrm{ml} \mathrm{Cu}\left(\mathrm{NO}_{3}\right)_{2}$ standard solution $\mathrm{I}$ to $1,000 \mathrm{ml}$ with metal-free water containing one or two drops of concentrated $\mathrm{HNO}_{3}$.

Copper nitrate standard working solutions : Prepare a series of standard solutions containing from 0.00 to $1.0 \mathrm{mg}$ copper per liter by diluting the $\mathrm{Cu}\left(\mathrm{NO}_{3}\right)_{2}$ standard solution II.

\section{PROCEDURE}

1. Filter the sample $(0.45 \mu$ micropore membrane filter $)$ Then necessary to avoid clogging the atomizer-burner.

2. Atomize each sample and standard, and record the scale readings observed. Repeat, and average the two values.

\section{CALCULATIONS}

1. Determine the copper concentration in the sample from a plot of scale readings of standards. Because a scale expansion of $10 \times$ is used, scale readings need not be converted to absorbance. Exact reproducibility is not obtained, and a working curve must be prepared with each set of samples. 
2. ppm copper $=\frac{1}{\text { density }} \times$ mg copper per liter.

Report copper concentrations less than $1.0 \mathrm{ppm}$ to the nearest $0.01 \mathrm{ppm}$, and those greater than $1.0 \mathrm{ppm}$ to two signficant figures.

\section{LITHIUM}

\section{DISCUSSION OF METHOD}

A hollow-cathode lamp is used to determine lithium. The lamp current must be high enough to prevent excessive noise; $20 \mathrm{ma}$ is suggested, although some lamps may require less. Highor currents are not recommended because the cathode will begin to melt at about 25$28 \mathrm{ma}$.

Concentrations of up to $1,000 \mathrm{ppm}$ sodium, $100 \mathrm{ppm}$ potassium, 200 ppm magnesium, $200 \mathrm{ppm}$ calcium, $1,500 \mathrm{ppm}$ chloride, $2,000 \mathrm{ppm}$ sulfate, and $100 \mathrm{ppm}$ nitrate do not interfere. Strontium, at concentrations greater than $5 \mathrm{ppm}$, interferes.

The $6708 \mathrm{~A}$ line is used to determine lithium. Since the detection limit is $0.005 \mathrm{mg}$ per 1 or less, three working curves ar 3 recommended to cover the concentration range $0-10 \mathrm{mg}$ lithium per liter. For the working curve $0.00-0.10 \mathrm{mg}$ lithium per liter, results are accurate and reproducible to approximately $\pm 0.002 \mathrm{mg}$ per 1 ; between 0.1 and 1.0 $\mathrm{mg}$ lithium per liter to $\pm 0.01 \mathrm{mg}$ per $\mathrm{l}$; and between 1.0 and $10 \mathrm{mg}$ lithium per liter, to $\pm 0.1 \mathrm{mg}$ per 1 . There is excellent agreement between lithium concentrations determined by both the atc mic-absorption and the flame-photometric methods (Beckman DU flame photometer).

The sensitivity for lithium concentrations of less than $0.1 \mathrm{mg}$ per 1 is approximately $0.005 \mathrm{mg}$ per 1 for each scale division; for those between 0.1 and $1.0 \mathrm{mg}$ lithium per liter, approximately $0.01 \mathrm{mg}$ per 1 for each scale division; and for those greater than $1.0 \mathrm{mg}$ per l, approximately $0.1 \mathrm{mg}$ per 1 per 1 percent absorption. The method is applicable to both fresh waters and brines. Brines must be diluted to concentrations of $15,000 \mathrm{ppm}$ or less total dissolved solids.

\section{APPARATUS}

Concentration range: $1.0-10 \mathrm{mg}$ lithium per liter

Grating: Visible

Wavelength counter: 335.4 (6708 A)

Scale: $1 \times$

Slit : 5 ( $3 \mathrm{~mm}, 40 \mathrm{~A})$

Source: Lithium hollow-cathode lamp

Lamp current : 20 ma maximum

Air pressure: $28 \mathrm{psi}$; 9.0 on flowmeter (varies with different flowmeters and burners)

Fuel : Acetylene. Pressure: 8 psi ; 9.0 on flowmeter 


\section{Flame: Oxidizing}

Sample uptake: About $4 \mathrm{ml}$ per min

Response-time control: 1

The following absorption readings have been observed :

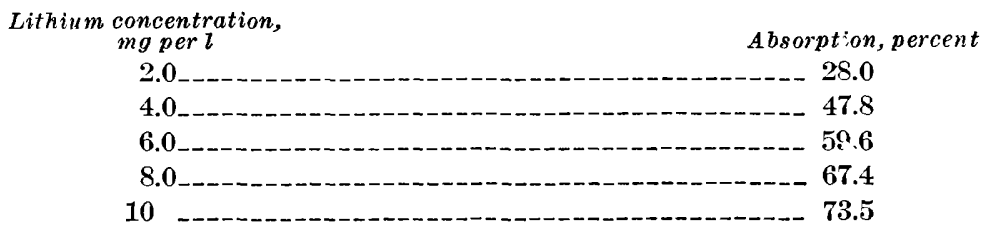

Concentration range : $0.1-1.0 \mathrm{mg}$ lithium per liter.

Scale: $5 \times$

All other operating conditions the same as used for concentration range from 1.0 to $10 \mathrm{mg}$ lithium per liter.

The following readings have been observed:

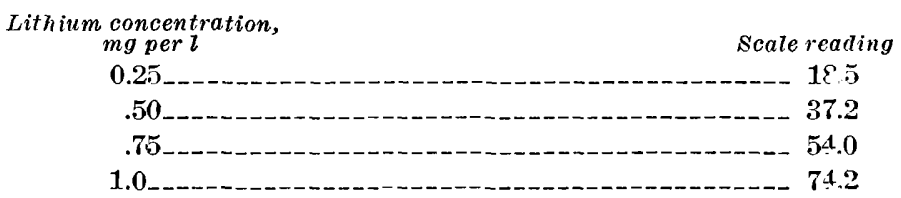

Concentration range: $0.00-0.10 \mathrm{mg}$ lithium per liter.

Scale: $10 \times$

All other operating conditions the same as used for concentration range from 1.0 to $10 \mathrm{mg}$ lithium per liter.

The following readings have been observed :

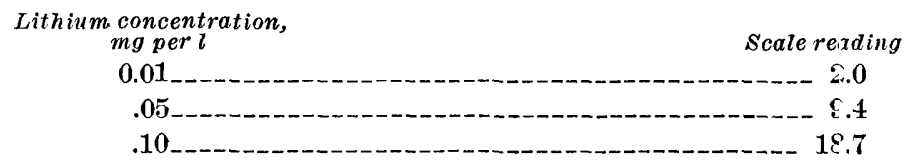

REAGENTS

Lithium nitrate standard stock solution, $1.00 \mathrm{ml}=1.00 \mathrm{mg}$ lithium: Dissolve $9.9357 \mathrm{~g} \mathrm{LiNO}_{3}$ in demineralized water and dilute to 1,000 $\mathrm{ml}$.

Lithium nitrate standard working solutions: Prepare a series of standard solutions containing from 0 to $10 \mathrm{mg}$ lithium per liter by diluting: the $\mathrm{LiNO}_{3}$ standard stock solution.

\section{PROCEDURE}

1. Filter the sample $(0.45 \mu$ micropore membrane filter $)$ when necessary to a void clogging the atomizer-burner.

2. Atomize each sample and standard, and record the percent absorption or scale reading observed. Repeat, and average the two values. If the lithium concentration is greater than $10 \mathrm{mg}$ per 1 , the sample must be diluted. 


\section{Catculations}

1. Concentration range $1.0-10 \mathrm{mg}$ lithium per liter: Convert percent absorption to absorbance, and determine the lithium concentration in the sample from a plot of absorbances of standards. For samples containing more than $10 \mathrm{mg}$ lithium per liter, multiply by proper dilution factor.

2. Concent ration ranges $0.10-1.0 \mathrm{mg}$ lithium per liter and $0.00-0.10 \mathrm{mg}$ lithium per liter: Determine the lithium concantration in the sample from a plot of scale readings of standards. Because scale expansion's of $5 \times$ and $10 \times$ are used, scale reac'ings need not be converted to absorbance.

3. ppm lithium $=\frac{1}{\text { density }} \times \mathrm{mg}$ lithium per liter.

Report lithium concentrations less than $0.10 \mathrm{ppm}$ to the nearest $0.005 \mathrm{ppm}$, those between 0.10 and $1.0 \mathrm{ppm}$ to the nearest $0.01 \mathrm{ppm}$, those between 1.0 and $10 \mathrm{ppm}$ to the nearest $0.1 \mathrm{ppm}$, and those greater than 10 ppm to whole numbers.

\section{MAGNESIUM}

\section{DISCUSSION OF METHOD}

A hollow-cathode lamp and a reducing flame are used to determine magnesium. Two magnesium lines - one at $2852 \mathrm{~A}$, and the groundstate line at $2025 \mathrm{~A}$-are employed to avoid excessive dilution of samples. Aluminum, in concentrations greater than $2 \mathrm{ppm}$, interferes at both lines; sulfate and phosphate interfere at the $2025 \mathrm{~A}$ line. These interferences, however, are masked by the addition of approximately 1 percent lanthanum. Low magnesium values result if the $\mathrm{pH}$ of the sample is above 7 ; therefore, both standards and samples are prepared in 5-percent hydrochloric acid solution. Sodium, potassium, and calcium, in concentrations less than $400 \mathrm{ppm}$, show no interference. There is also a zinc line at $2025 \mathrm{~A}$, but $2 \mathrm{ppm}$ zinc shows no interference.

The $2852 \mathrm{~A}$ line is used to determine concentrations of magnesium less than $2 \mathrm{mg}$ per $\mathrm{l}$. Magnesium concentrations of $2-10 \mathrm{mg}$ per 1 are determined using the same line by dilution of the sample. The $2025 \mathrm{~A}$ line is used to determine magnesium concentrations between 10 and 50 $\mathrm{mg}$ per 1 . To determine magnesium concentrations greater than 50 $\mathrm{mg}$ per l, dilution is required.

For magnesium concentrations of less than $10 \mathrm{mg}$ per l, results are accurate and reproducible to $\pm 0.1 \mathrm{mg}$ per $\mathrm{l}$, and with extreme care the results are accurate and reproducible to $\pm 0.02 \mathrm{mg}$ per l at concentrations less than $2 \mathrm{mg}$ per 1 without scale expansion. The results are accurate and reproducible to $\pm 1 \mathrm{mg}$ per 1 for concentrations of mag- 
nesium between 10 and $50 \mathrm{mg}$ per 1 . When dilution is required, for samples containing more than $50 \mathrm{mg}$ per 1 , the accuracy and reproducibility are decreased. There is excellent agreement between results obtained by atomic absorption and those obtained by EDTA titration for samples containing 10-50 mg magnesium per liter.

The sensitivity for magnesium concentrations of less than $2 \mathrm{mg}$ per 1 is approximately $0.03 \mathrm{mg}$ per 1 per 1 percent absorption. For the 10$50 \mathrm{mg}$ magnesium per liter range, the sensitivity is approximately 1 mg per 1 per 1 percent absorption.

\section{APPARATUS}

Concentration range : 0-10 mg magnesium per liter (samples containing more than $2 \mathrm{mg}$ magnesium per liter must be diluted)

Grating: Ultraviolet

Wavelength counter: $285.2(285.2 \mathrm{~A})$

Scale: $1 \times$

Slit: 5 ( $3 \mathrm{~mm}, 20 \mathrm{~A})$

Source: Magnesium hollow-cathode lamp

Lamp current: $10 \mathrm{ma}$

Air pressure: $28 \mathrm{psi} ; 8.0$ on flowmeter

Fuel: Acetylene. Pressure: 8 psi; 9.0 on flowmeter initially (use a $1 \mathrm{mg}$ magnesium per liter standard solutior. and adjust acetylene flow rate to obtain maximum absorntion)

Flame: Reducing

Sample uptake: About $4 \mathrm{ml}$ per min

The following absorption readings have been observed:

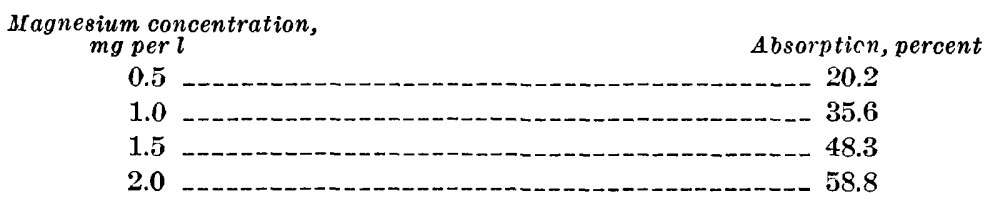

Concentration range: $10-50 \mathrm{mg}$ magnesium per liter

Wavelength counter : 202.5 (2025 A)

Response-time control : 1

All other operating conditions same as used for concentration range $0-10 \mathrm{mg}$ magnesium per liter.

The following absorption readings have been observed:

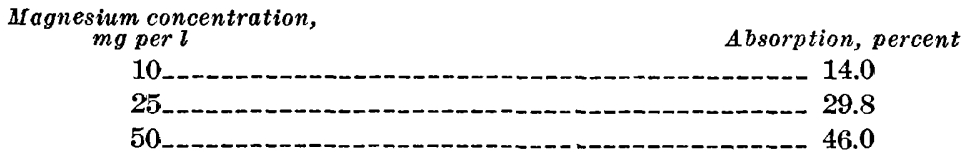




\section{REAGENTS}

Lanthanum chloride-hydrochloric acid solution: Dissolve $58.65 \mathrm{~g}$ of $\mathrm{La}_{2} \mathrm{O}_{3}$, slowly and in small portions, in $250 \mathrm{ml}$ concentrated $\mathrm{HCl}$ (CAUTION! Reaction is violent) and dilute to $509 \mathrm{ml}$ with distilled water.

Magnesium chloride standard stock solution, $1.00 \mathrm{ml}=0.50 \mathrm{mg}$ magnesium: Dissolve $0.500 \mathrm{mg}$ pure metallic magnesium in a minimum amount of dilute $\mathrm{HCl}$ and dilute to $1,000 \mathrm{ml}$ with distilled water.

Magnesium chloride standard working solutions: Prepare a series of standard solutions containing from 0 to $50 \mathrm{mg}$ ms gnesium per liter by diluting the $\mathrm{MgCl}_{2}$ standard stock solution. A dd $1.0 \mathrm{ml} \mathrm{\textrm {LaCl } _ { 3 } -}$ $\mathrm{HCl}$ solution to each $10.0 \mathrm{ml}$ of the working standards prepared. For example, to $500 \mathrm{ml}$ of a working standard, add $50 \mathrm{ml} \mathrm{\textrm {LaCl } _ { 3 } -}$ $\mathrm{HCl}$ solution.

\section{PROCEDURE}

1. Filter the sample $(0.45 \mu$ micropore membrane filter $)$ when necessary to avoid clogging the atomizer-burner.

2. Add $1.0 \mathrm{ml}$ of $\mathrm{LaCl}_{3}-\mathrm{HCl}$ solution to $10.0 \mathrm{ml}$ of sample.

3. Atomize each sample and standard, and record the percent absorption observed. Repeat, and average the two values. If the magnesium concentration is greater than $50 \mathrm{mg}$ per l, the sample must be diluted. Be sure that the diluted sample contains the proper amount of $\mathrm{LaCl}_{3}-\mathrm{HCl}$ solution.

\section{CALCULATIONS}

1. Convert percent absorption to absorbance, and determine the magnesium concentration in the sample from a plot of absorbances of standards. For samples containing more than $2 \mathrm{mg}$ magnesium per liter (0-2 mg magnesium per liter working curve) or more than $50 \mathrm{mg}$ magnesium per liter (10-50 mg magnesium per liter working curve) multiply by the proper dilution factor. Exact reproducibility is not obtained, and working curves must be prepared with each set of samples.

2. ppm magnesium $=\frac{1}{\text { density }} \times$ mg magnesium per liter.

Report magnesium concentrations less than $10 \mathrm{ppm}$ to the nearest $0.1 \mathrm{ppm}$, those between 10 and $200 \mathrm{ppm}$ to the nearest whole number, and those greater than $2(10 \mathrm{ppm}$ to two significant figures. 
MANGANESE

\section{DISCUSSION OF METHOD}

A hollow-cathode lamp is used to determine manganese, and the lamp should be allowed to warm up for about 30 minutes before use. The optimum current may differ slightly for different lamps. However, currents greater than the maximum stated on the lamp should not be used because the cathode may melt.

The $2795 \mathrm{~A}$ line is used to determine manganese. Although there are two iron lines and a magnesium line near this line, concentrations of up to $25 \mathrm{ppm}$ iron, $100 \mathrm{ppm}$ magnesium show no interference. Magnesium in concentrations greater than $100 \mathrm{ppm}$ interferes when the manganese concentration exceeds $0.50 \mathrm{ppm}$. However, magnesium does not interfere when other cations, such as sodium, are present in the sample. Other cations and anions normally found in water do not inter'fere.

To determine manganese concentrations of less than $1.0 \mathrm{mg}$ per 1 , $10 \times$ scale expansion is used. Results are accurate and reproducible to approximately $\pm 0.02 \mathrm{mg}$ manganese per liter. Consentrations greater than $1.0 \mathrm{mg}$ per $\mathrm{l}$ are determined directly by using less scale expansion. The maximum concentration that can be deternined at the $2795 \mathrm{~A}$ line without dilution is about $25 \mathrm{mg}$ manganese per liter.

The sensitivity for manganese concentrations of less tran $1.0 \mathrm{mg}$ per 1 is approximately $0.02 \mathrm{mg}$ per 1 for each scale division.

Grating: Ultraviolet

APPARATUS

Wavelength counter : $279.5(2795 \mathrm{~A})$

Scale : $10 \times$

Slit : 4 (1 mm, 6.5 A)

Source: Manganese hollow cathode lamp

Lamp current : 10-15 ma

Air pressure : $28 \mathrm{psi} ; 9.0$ on flowmeter (varies with different flowmeters and burners)

Fuel : Acetylene. Pressure : 8 psi, 9.0 on flowmeter

Flame: Oxidizing

Sample uptake : $3-5 \mathrm{ml}$ per min

Response-time control: 1

The following readings have been observed:

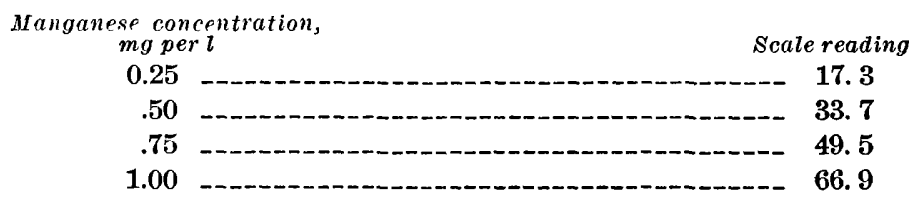




\section{REAGENTS}

Manganous sulfate standard solution $\mathrm{I}, 1.00 \mathrm{ml}=0.107 \mathrm{mg}$ manganese : Heat $0.5 \mathrm{~g} \mathrm{MnSO}_{4} \cdot \mathrm{H}_{2} \mathrm{O}$ for 1 hour at $180^{\circ} \mathrm{C}$. Dissolve $0.2749 \mathrm{~g}$ in demineralized water containing $1 \mathrm{ml}$ concentrated $\mathrm{H}_{2} \mathrm{SO}_{4}$ (specific gravity 1.84). Add $2.0 \mathrm{ml}$ formalin to inhibit mold growth, and dilute to $1,000 \mathrm{ml}$ with demineralized water.

Manganous sulfate standard solution II, $1.00 \mathrm{ml}=0.010 \mathrm{mg}$ manganese: Immediately before use, dilute $10 \mathrm{ml}$ of $\mathrm{MnSO}_{4}$ standard solution I to $100 \mathrm{ml}$ with demineralized water.

Manganous sulfate standard working solutions: Prapare a series of standard solutions containing from 0.00 to $1.0 \mathrm{mg}$ manganese per liter by diluting the $\mathrm{MnSO}_{4}$ standard solution II.

\section{PROCEDURE}

1. Filter the sample ( $0.45 \mu$ micropore membrane filter) when necessary to avoid clogging the atomizer burner.

2. Atomize each sample and standard, and record the scale reading observed. Repeat, and average the two values.

\section{CALCULATIONS}

1. Determine the manganese concentration in the sample from a plot of scale readings of standards. Because a scale expansion of $10 \times$ is used, the scale readings need not be converted to absorbance. Exact reproducibility is not obtained, and a working curve must be prepared with each set of samples.

2. ppm manganese $=\frac{1}{\text { density }} \times$ mg manganese per liter.

Report manganese concentrations less than $1.0 \mathrm{ppm}$ to the nearest $0.01 \mathrm{ppm}$ and those greater than $1.0 \mathrm{ppm}$ to two significant figures.

\section{POTASSIUM}

\section{DISCUSAION OF METHOD}

A vapor-discharge lamp operating at $350 \mathrm{ma}$ is used to determine potassium. Some lamps may require a source current of $500 \mathrm{ma}$ if the potassium arc is unstable, if absorption values are low, or if there is excessive noise. Additional current often produces considerably more light, and a smaller slit width may be required.

The $7665 \mathrm{~A}$ line is used to determine potassium. O ly sodium interferes, and approximately equivalent amounts of sodium must be present in both standards and samples. At any given sodium concentration up to $1,000 \mathrm{mg}$ per 1 , the actual sodium concentration may vary 
by as much as $\pm 50 \mathrm{mg}$ per 1 without a significant effect on the amount of potassium observed. Therefore, $200 \mathrm{mg}$ sodium per liter is added to each standard, and each sample is so prepared that its sodium concentration is between 150 and $250 \mathrm{mg}$ per 1 . Results are acsurate and reproducible to $\pm 0.1 \mathrm{mg}$ per 1 for potassium concentrations of less than $10 \mathrm{mg}$ potassium per liter, and to $\pm 0.1- \pm 1.0 \mathrm{mg}$ per 1 for concentrations of potassium from 10 to $100 \mathrm{mg}$ per l. When excessive dilution is required, the accuracy and reproducibility are decreased. With scale expansion, results are accurate and reproducible to \pm 0.01 mg per 1 for potassium concentrations of less than $1 \mathrm{mg}$ per $\mathrm{l}$.

The sensitivity for potassium concentrations of less than $10 \mathrm{mg}$ per $\mathrm{l}$ is approximately $0.1 \mathrm{mg}$ per $\mathrm{l}$ per 1 percent absorption.

The atomic absorption method is applicable to a wide range of potassium concentrations, such as traces in rainwater and as much as 7,000 $\mathrm{mg}$ per $\mathrm{l}$ in brines. For samples containing concentrations of potassium greater than $10 \mathrm{mg}$ per l, dilution is required.

Grating: Visible

APPARATUS

Wavelength counter : $383.2(7665 \mathrm{~A})$

Scale: $1 \times$

Slit: 5 (3 mm, $40 \mathrm{~A})$

Source: Osram potassium-rapor-discharge lamp

Lamp current : 350 ma, or optimum operating current

Air pressure : $28 \mathrm{psi} ; 9.0$ on flowmeter (varies with different flowmeters and burners)

Fuel : Acetylene. Pressure : 8 psi; 9.0 on flowmeter

Flame: Oxidizing

Sample uptake: About $4 \mathrm{ml}$ per min

The following absorption readings have been observed :

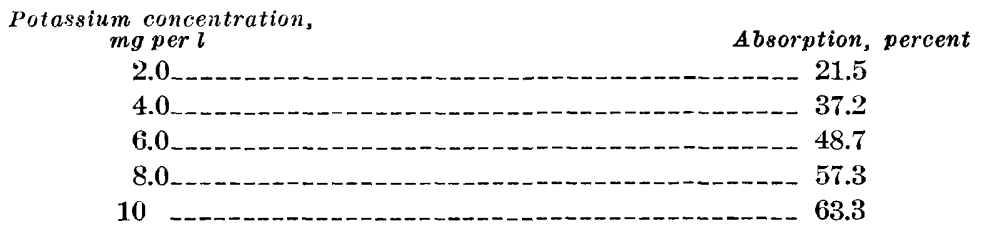

REAGENTS

Potassium chloride standard stock solution, $1.00 \mathrm{ml}=0.10 \mathrm{mg}$ potassium: Dissolve $0.1907 \mathrm{~g} \mathrm{KCl}$ in demineralized water and dilute to $1,000 \mathrm{ml}$.

Potassium chloride standard working solutions: Prepare a series of standard solutions containing from 0 to $10 \mathrm{mg}$ potassium and $200 \mathrm{mg}$ sodium per liter by diluting the potassium standard stock solution and the $\mathrm{NaCl}$ standard stock solution. 
Sodium chloride standard stock solution, $1.00 \mathrm{ml}=1.00 \mathrm{mg}$ sodium: Dissolve $2.542 \mathrm{~g} \mathrm{NaCl}$ in demineralized water and c'ilute to $1,000 \mathrm{ml}$.

\section{PROCEDURE}

1. Filter the sample $\left(0.45 \mu\right.$ micropore membrane fil ${ }^{+}$er $)$when necessary to avoid clogging the atomizer-burner.

2. Adjust the sodium concentration of each sample to between 150 and $250 \mathrm{mg}$ per 1 by adding the calculated volume of the $\mathrm{NaCl}$ standard stock solution.

3. Atomize each sample and standard, and record the percent absorption observed. Repeat, and average the two values. If the concentration is greater than $10 \mathrm{mg}$ per l, the sample must be diluted. Be sure that the diluted sample contains between 150 and $250 \mathrm{mg}$ sodium per liter.

\section{Calculations}

1. Convert percent absorption to absorbance, and determine the potassium concentration in the sample from a plot, of absorbances of standards. For samples containing more than $10 \mathrm{mg}$ potassium per liter, multiply by the proper dilution factor. Also, if the sample was adjusted to contain between 150 and $250 \mathrm{mg}$ sodium per liter, multiply by the proper dilution factor. Exact reproducibility is not obtained, and a working curve must be prepared with each set of samples.

2. ppm potassium $=\frac{1}{\text { density }} \times$ mg potassium per liter.

Report potassium concentrations less than $10 \mathrm{ppm}$ to the nearest $0.1 \mathrm{ppm}$, those between 10 and $1,000 \mathrm{ppm}$ to the nearest whole number, and those greater than $1,000 \mathrm{ppm}$ to three significant figures.

\section{SODIUM}

\section{DISCUSSION OF METHOD}

A vapor-discharge lamp is used to determine sodium. The exact slit width and lamp current differs with the lamp used. The lamp current should be increased until the color of the arc is the characteristic yellow orange of the sodium discharge. Additional current often produces considerably more light and a smaller slit width may be required; a decrease in current has the opposite effect.

To avoid excessive dilution of the sample, two sodium lines are used. For waters containing less than $10 \mathrm{mg}$ sodium per liter, the $5890 \mathrm{~A}$ line is used, and for those containing more than $10 \mathrm{mg}$ per l, the weaker resonance line at $3302 \mathrm{~A}$ is used. Two working curves are prepared 
for the $3302 \mathrm{~A}$ line: one for the sodium concentration rance $6-60 \mathrm{mg}$ per $\mathrm{l}$, and another for the range 40-200 $\mathrm{mg}$ sodium per liter.

Other elements found in water do not interfere, and the results are accurate and reproducible to $\pm 0.1 \mathrm{mg}$ per 1 for sodium concentrations of less than $10 \mathrm{mg}$ per $\mathrm{l}$, and to $\pm 1- \pm 2 \mathrm{mg}$ per 1 for sodium concentrations between 10 and $200 \mathrm{mg}$ per $\mathrm{l}$.

The sensitivity for sodium concentrations of less than $10 \mathrm{mg}$ per 1 is approximately $0.05 \mathrm{mg}$ per 1 per 1 percent absorption; for concentrations between 10 and $40 \mathrm{mg}$ per 1, approximately $1 \mathrm{mg}$ per 1 for each scale division; and concentrations greater than $40 \mathrm{mg}$ per l, s.bout $3 \mathrm{mg}$ per 1 for each scale division.

The atomic absorption method is applicable to a wide range of sodium concentrations-from traces in rainwater and to $100,000 \mathrm{mg}$ per 1 in brines. For samples containing more than $200 \mathrm{mg}$ per l, dilution is required.

\section{APPARATUS}

Concentration range : $0.0-10 \mathrm{mg}$ sodium per liter

Grating: Visible

Wavelength counter : 294.4 (5888 A)

Scale: $1 \times$

Slit : $3(0.3 \mathrm{~mm}, 4.0 \mathrm{~A})$

Source: Osram sodium-vapor discharge lamp

Lamp current : $900 \mathrm{ma}$, or optimum operating current

Air pressure: $28 \mathrm{psi} ; 9.0$ on flowmeter (varies with different flowmeters and burners)

Fuel : Acetylene. Pressure: 8 psi; 9.0 on flowmeter

Flame: Oxidizing

Sample uptake: About $4 \mathrm{ml}$ per $\mathrm{min}$

The following absorption readings have been observed:

Sodium concentration, mg per $l$

Absorption, pe“cent

2.0

4.0

6.0

8.0

10 - 10.4

Concentration range : $6-60 \mathrm{mg}$ sodium per liter

Grating: Ultraviolet

Wavelength counter : $330.2(3302 \mathrm{~A})$

Scale: $5 \times$

Slit: 4 (1 mm, $13 \mathrm{~A})$

All other operating conditions same as used for concentration range $0.0-10 \mathrm{mg}$ sodium per liter. 
The following readings have been observed:

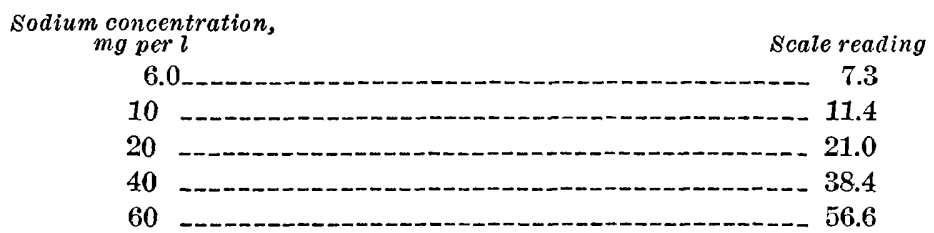

Concentration range : 40-200 mg sodium per liter

Grating: Ultraviolet

Wavelength counter : $330.2(3302 \mathrm{~A})$

Scale: $2 \times$

Slit: $4(1 \mathrm{~mm}, 13 \mathrm{~A})$

All other operating conditions same as used for concentration range $0.0-10 \mathrm{mg}$ sodium per liter.

The following absorption readings have been observed :

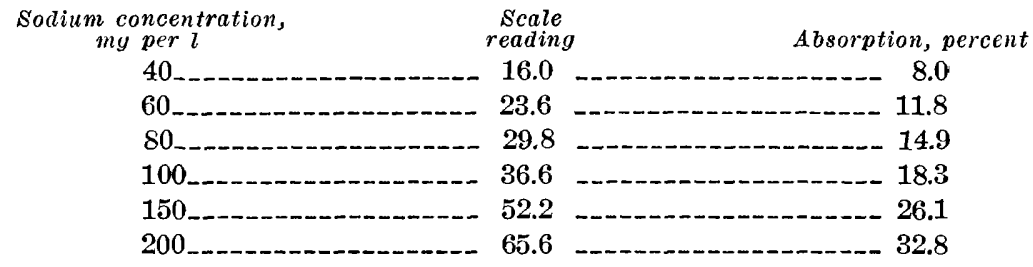

\section{REAGENTS}

Sodium chloride standard stock solution, $1.00 \mathrm{ml}=1.00 \mathrm{mg}$ sodium: Dissolve $2.542 \mathrm{~g} \mathrm{NaCl}$ in demineralized water and dilute to $1,000 \mathrm{ml}$. Sodium chloride standard working solutions: Prepare a series of standard solutions containing from 0 to $200 \mathrm{mg}$ sodium per liter by diluting the $\mathrm{NaCl}$ standard stock solution.

\section{PROCEDURE}

1. Filter the sample $(0.45 \mu$ micropore membrane filter $)$ when necessary to avoid clogging the atomizer-burner.

2. Atomize each sample and standard, and record the percent absorption or scale reading observed. Repeat, and average the two values. If the sodium concentration is greater than $200 \mathrm{mg}$ per 1 , the sample must be diluted.

\section{Calculations}

1. Concentration range $0.0-10 \mathrm{mg}$ sodium per liter: Convert percent absorption to absorbance, and determine the sodium concentration in the sample from a plot of absorbances of standards.

2. Concentration range 6-60 $\mathrm{mg}$ sodium per liter: Determine the sodium concentration in the sample from a plot $\mathrm{c} f$ scale readings 
of standards. Because a scale expansion of $5 \times$ is used, scale readings need not be converted to absorbance.

3. Concentration range $40-200 \mathrm{mg}$ sodium per liter: Divide the scale reading by 2 to obtain percent absorption. Convert to absorbance, and determine the sodium concentration in the sample from a plot of absorbances of standards. For samples containing more than $200 \mathrm{mg}$ sodium per liter, multiply by the proper dilution factor. Exact reproducibility is not obtained, and working curves must be prepared with each set of samples.

4. $\mathrm{ppm}$ sodium $=\frac{1}{\text { density }} \times \mathrm{mg}$ sodium per liter.

Report sodium concentrations less than $10 \mathrm{ppm}$ to the nearest 0.1 ppm, those between 10 and $1,000 \mathrm{ppm}$ to the nearest whole number, and those greater than $1,000 \mathrm{ppm}$ to three significant figures.

\section{STRONTIUM}

\section{DISCUSSION OF METHOD}

A hollow-cathode lamp and a reducing flame are used to determine strontium. Sodium and potassium decrease the strontium ionization in the flame. This effect levels off above concentrations of $100 \mathrm{ppm}$ of either sodium or potassium. To control the ionization, 1,000 ppm of potassium is added to both standards and samples. A luminum, phosphate, and silica interfere but are masked by the addition of lanthanum. No interferences occur for concentrations of up to 50 ppm nitrate and 2,000 ppm each of sulfate, magnesium, and calcium. Above 2,500 ppm total dissolved solids, and depending upon the ratio of strontium to total dissolved solids present, low strontium values result even in the presence of potassium and lanthanum. Therefore, the standard-addition technique must be used for highly mineralized waters or for brines containing more than $2,500 \mathrm{ppm}$ total dissolved solids.

The 4607 A line is used to determine concentrations of strontium less than $20 \mathrm{mg}$ per 1 . Two working curves are required. Results are accurate and reproducible to approximately $\pm 0.02 \mathrm{mg}$ per 1 for the concentration range $0.00-1.0 \mathrm{mg}$ strontium per liter. For the concentration range $1.0-20 \mathrm{mg}$ per 1 , results are accurate and reproducible to approximately $\pm 0.1 \mathrm{mg}$ per $\mathrm{l}$ for concentrations less than $10 \mathrm{mg}$ per 1 , and to approximately $\pm 0.5 \mathrm{mg}$ per 1 for concentrations greater than $10 \mathrm{mg}$ per $\mathrm{l}$.

The sensitivity for strontium concentrations of less than $1.0 \mathrm{mg}$ per 1 is approximately $0.02 \mathrm{mg}$ per 1 for each scale division, and for concentrations between 1 and $20 \mathrm{mg}$ per 1 , approximately $0.2-0.3 \mathrm{mg}$ per 1 per 1 percent absorption. 


\section{APPARATUS}

Concentration range: $1.0-20 \mathrm{mg}$ strontium per liter

Grating: Visible

Wavelength counter: 230.4 (4607 A)

Scale : $1 \times$

Slit : $4(1 \mathrm{~mm}, 13 \mathrm{~A})$

Source: Strontium hollow-cathode lamp

Lamp current: $15 \mathrm{ma}$

Air pressure: $28 \mathrm{psi} ; 8.0$ on flowmeter

Fuel : Acetylene. Pressure: 8 psi, 9.0 on flowmeter initially (use a $10 \mathrm{mg}$ strontium per liter standard solution and adjust acetylene flow rate to obtain maximum absorption)

Flame: Reducing

Sample uptake: About $4 \mathrm{ml}$ per min

The following absorption readings have been observed:

Strontium concentration, $m g$ per $l$

Absorption, percent

1.0

5.6

$$
5.0
$$

24. 5

10

41.5

15

53. 0

20 62.6

Concentration range: $0.00-1.0 \mathrm{mg}$ strontium per liter

Scale : $10 \times$

Response-time control : 1

All other operating conditions same as used for concentration range 1.0-20 mg strontium per liter.

The following readings have been observed :

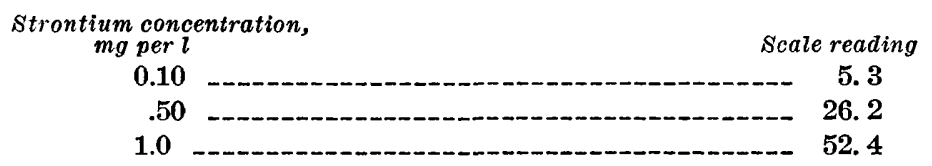

\section{REA GENTS}

Lanthanum chloride-potassium chloride solution: Dissolve $117.3 \mathrm{~g}$ $\mathrm{La}_{2} \mathrm{O}_{3}$ in a minimum amount of dilute $\mathrm{HCl}$. Add $19.1 \mathrm{~g} \mathrm{KCl}$, and dilute to $1,000 \mathrm{ml}$ with distilled water.

Strontium chloride standard stock solution, $1.00 \mathrm{ml}=0.10 \mathrm{mg}$ strontium: Dissolve $0.1684 \mathrm{~g}$ of $\mathrm{SrCO}_{3}$ in a minimum amount of dilute $\mathrm{HCl}$, and dilute to $1,000 \mathrm{ml}$.

Strontium chloride standard working solutions: Prepare a series of solutions containing from 0 to $20 \mathrm{mg}$ strontium per liter by diluting the $\mathrm{SrCl}_{2}$ standard stock solution. Add $1.0 \mathrm{ml}$ of $\mathrm{La} \mathrm{Cl}_{3}-\mathrm{KCl}$ solution to each $10.0 \mathrm{ml}$ of the working standards prepared. For exam-

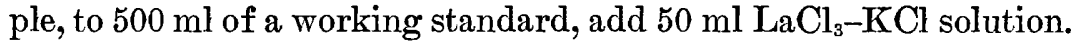




\section{PROCEDURE}

1. Filter the sample ( $0.45 \mu$ micropore membrane filter) when necessary to avoid clogging the atomizer-burner.

2. Add $1.0 \mathrm{ml} \mathrm{LaCl}_{3}-\mathrm{KCl}$ solution to $10.0 \mathrm{ml}$ of sample.

3. Atomize each sample and standard, and record the percent absorption or scale reading observed. Repeat, and average the two values. If the strontium concentration is greater than $20 \mathrm{mg}$ per $\mathrm{l}$, the sample must be diluted. Be sure that the diluted sample contains the proper amount of $\mathrm{LaCl}_{3}-\mathrm{KCl}$ solution.

\section{CaIcurations}

1. Concentration range $1.0-20 \mathrm{mg}$ strontium per liter: Convert percent absorption to absorbance, and determine the strontium concentration in the sample from a plot of absorbances of standards. For samples containing more than $20 \mathrm{mg}$ per 1 , raultiply by proper dilution factor.

2. Concentration range $0.00-1.0 \mathrm{mg}$ strontium per liter: Determine the strontium concentration in the sample from a plot of scale readings of standards. Because a scale expansion of $10 \times$ is used, scale readings need not be converted to absorbance. Exact reproducibility is not obtained, and working curves must be prepared with each set of samples.

3. ppm strontium $=\frac{1}{\text { density }} \times$ mg strontium per liter.

Report strontium concentrations less than $1: 0 \mathrm{ppm}$ to the nearest $0.01 \mathrm{ppm}$, those between 1.0 and $10 \mathrm{ppm}$ to the nearest $0.1 \mathrm{ppm}$, and those greater than $10 \mathrm{ppm}$ to the nearest whole rumber.

\section{ZINC}

\section{DISCUSSION OF METHOD}

A hollow-cathode lamp is used to determine zinc. The lamp should be allowed to warm up for about 30 minutes at a current c 12 ma before use. The lamp current is then optimized by adjusting the source control to obtain a minimum noise level (not more than one or two divisions on the null meter). The final setting should be between 10 and $15 \mathrm{ma}$ and should not exceed the maximum stated on the lamp because the cathode will begin to melt.

The $2138 \mathrm{~A}$ line is used to determine zinc. Of the cations and anions normally found in water, only magnesium interferes. Magnesium concentrations greater than $100 \mathrm{ppm}$ interfere unless other crions, such as sodium, are present in the simple. There is currently no explanation for this phenomenon. 
To determine zinc at concentrations of less than $0.4 \mathrm{mg}$ per $1,10 \times$ scale expansion is used, and results are accurate and reproducible to approximately $\pm 0.02 \mathrm{mg}$ per 1 . Concentrations of zinc greater than $0.4 \mathrm{mg}$ per 1 can be determined by using less scale expansion. The maximum concentration that can be determined at the $2138 \mathrm{~A}$ line without dilution is $10 \mathrm{mg}$ zinc per liter.

The sensitivity for concentrations of zinc of less than $0.4 \mathrm{mg}$ per 1 is approximately $0.005 \mathrm{mg}$ per $\mathrm{l}$ for each scale division.

\section{APPARATUS}

Grating: Ultraviolet

Wavelength counter: 213.8 (2138 A)

Scale : $10 \times$

Slit : $5(3 \mathrm{~mm}, 20 \mathrm{~A})$

Source: Zinc hollow-cathode lamp

Lamp current: 12 ma, or optimum operating current

Air pressure: $30 \mathrm{psi} ; 9.0$ on flowmeter (varies with different flowmeters and burners)

Fuel: Acetylene. Pressure: 8 psi, 9.0 on flowmeter

Flame: Oxidizing

Sample uptake: $2-5 \mathrm{ml}$ per $\mathrm{min}$

Response-time control: 1 or 2

The following readings have been observed:

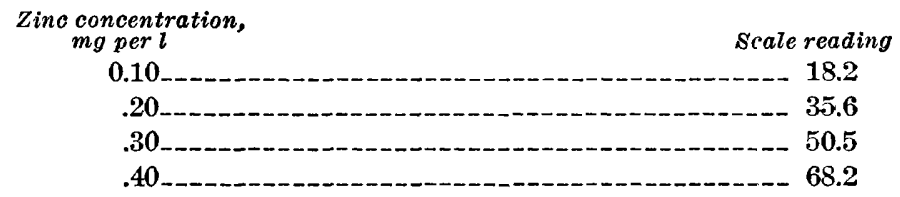

REAGENTS

Zinc chloride standard solution $\mathrm{I}, 1.00 \mathrm{ml}=0.100 \mathrm{mg}$ zinc: Dissolve $0.100 \mathrm{mg}$ reagent-grade zinc (30-mesh) in a slight $\epsilon$.xcess of $\mathrm{HCl}$, and dilute to $1,000 \mathrm{ml}$ with demineralized water.

Zinc chloride standard solution II, $1.00 \mathrm{ml}=0.100 \mathrm{mg}$ zinc: Immediately before use, dilute $10 \mathrm{ml}$ of $\mathrm{ZnCl}_{2}$ standard solution I to $100 \mathrm{ml}$ with demineralized water.

Zinc chloride standard working solutions: Prepare a series of standard solutions containing from 0.00 to $0.40 \mathrm{mg}$ zinc per liter by diluting the $\mathrm{ZnCl}_{2}$ standard solution II.

\section{PROCEDURE}

1. Filter the sample $(0.45 \mu$ micropore membrane filter $)$ when necessary to avoid clogging the atomizer-burner. 
2. Atomize each sample and standard, and record the sccle reading observed. Repeat, and average the two values.

\section{Calculatrons}

1. Determine the zinc concentration in the sample from a plot of scale readings of standards. Because a scale expansion of $10 \times$ is used, scale readings need not be converted to absorbance. Exact reproducibility is not obtained, and a working curre must be prepared with each set of samples.

2. $p$ pm zinc $=\frac{1}{\text { density }} \times m g$ zinc per liter.

Report zinc concentrations less than $1.0 \mathrm{ppm}$ to the rearest 0.01 $\mathrm{ppm}$ and those greater than $1.0 \mathrm{ppm}$ to two significant figures.

\section{REFERENCES}

Perkin-Elmer Corp., 1964, Analytical methods for atomic absorption spectrophotometry : Norwalk, Conn.

Walsh, Allan, 1955, The application of atomic absorption spectra to chemical analysis: Spectrochim. Acta, v. 7, p. 108-117. 



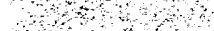

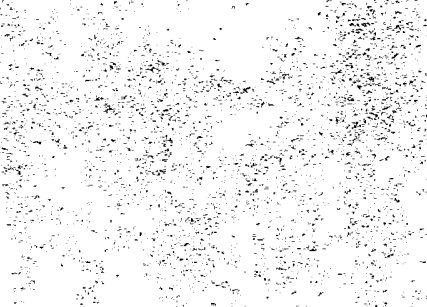

.

s.

the

th

4

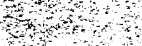

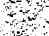

$\mathrm{kP}, \mathrm{n}$

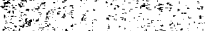

to

W $6 \mathrm{th}$

1.

$x^{2}+$

$3+4$

4

to

$+2$

th

w

$+$

8

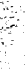

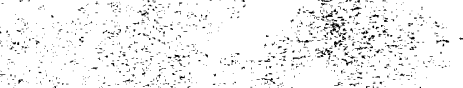

$x$

$+4$

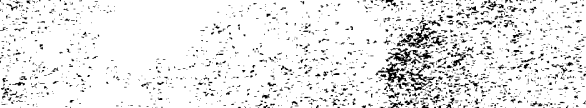

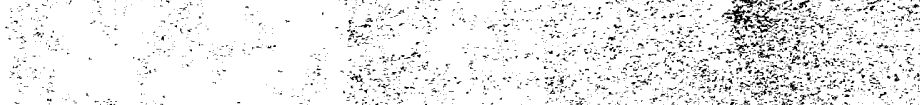

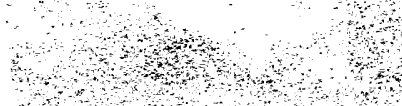

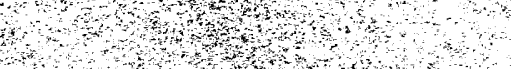

$+$

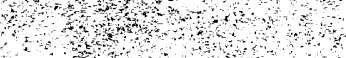

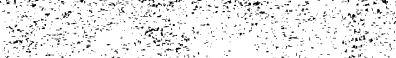

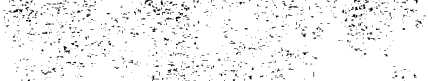

tont

3

the

te

Pand

48

5

s.

$+2$

8

8

s.t.

$+3$

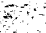

s.

$\mathrm{x}^{2} \mathrm{x}$

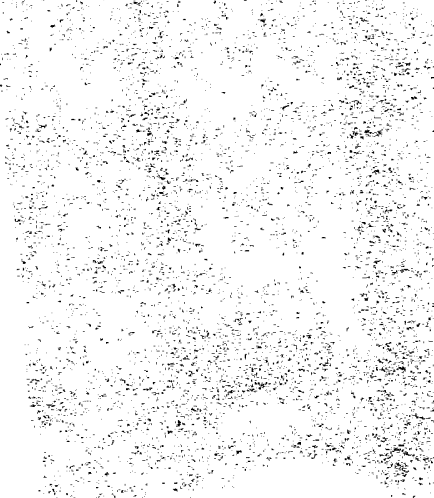

3. $+4+2$

$\mathrm{nt}$

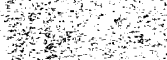

$\mathrm{rat}$

$\mathrm{moth}^{2}$

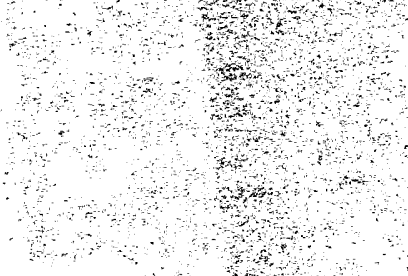

$x+3$ 


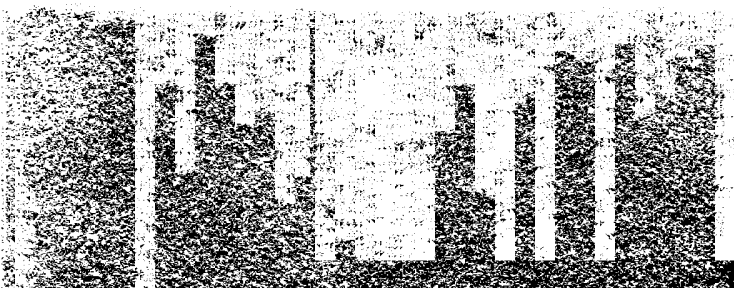

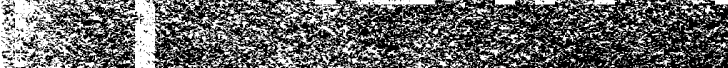

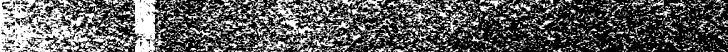
W, 